\title{
Insurance, Finance, Solvency II and Financial Market Interaction
}

\author{
Michael Butt \\ AXIS Capital Holdings Ltd, Chesney House, 1st Floor, 96 Pitts Bay Road, Pembroke HM 06, Bermuda. \\ E-mails: michael.butt@axis.bm, blythe.hurney@axiscapital.com
}

The convergence and interplay between the insurance sector and the capital markets is likely to increase as will the diversity of products the capital markets offer. The speed and depth of this increase will depend on the ability of the insurance sector to improve its data quality and its risk management practices, and the number and size of large losses in the next several years as the markets develop their knowledge. Ultimately, those insurers who have the best data collection and control will have a competitive edge in leveraging their own risk management franchises for stakeholders.

The Geneva Papers (2007) 32, 42-45. doi:10.1057/palgrave.gpp.2510115

Keywords: capital markets; Solvency II; sidecar; risk management; enterprise risk

In the post-Katrina debate, convergence of insurance markets with the broader capital markets, as well as the evolution of risk management practices and assessment of these practices critical to supporting this convergence, have taken center stage. The credibility factor has become very relevant with respect to evaluation of managements as good stewards of capital in our industry. In the face of credibility issues around management teams following insurance companies' recent performance, particularly during the 2005 hurricane season, capital providers have sought, and continue to seek out, ways to invest in discrete opportunities. In the most extreme cases, they are participating in opportunities mimicking transparent "bets on the weather'. This reality, coupled with the purest market forces, will strengthen and advance discipline around the measurement, management and communication of enterprise risk.

Since the 2005 hurricane season, the industry has faced substantially increased capital requirements. This is only partly driven by the increased frequency and severity of expected losses. The more dramatic impact has come from increased rating agency capital requirements per unit of exposure. As in previous market dislocations, incumbents looked to the capital markets to shore up balance sheets, new reinsurance companies were formed, largely in Bermuda, and catastrophe bond activity increased. It would appear that many commercial lines insurers and reinsurers have considered, and continue to consider, a range of options for the transfer of catastrophic risk to the capital markets, with particular emphasis on those alternatives that replicate the indemnity-based characteristics of traditional reinsurance providers. Ratings downgrades and market withdrawals post Katrina only highlight recoverable credit risk following a major cat event. Unique to this market dislocation is the advent of the "sidecar" to address investor demand for transfer of catastrophe risk, in particular. The sidecar concept is described in more detail later. Increased rating agency influence 
is not limited to enhanced capital requirements. Rating agencies have moved to standardize the provision of data and the discussion around capital at risk and to include an assessment of enterprise risk management in qualitative evaluations of insurance companies. All of this supports convergence of the insurance industry with the capital markets.

Also unique to this market dislocation is the profile of investor in the post-2005 insurance world. In the last few years, the investor universe in the insurance industry has broadened substantially and includes investors ranging from hedge funds with appetite for volatility and short term, "special" situations, to an ever-broadening base of private equity funds with appetite for franchise building. There is no doubt that hedge funds, in particular, have added significantly to the demand for transfer of catastrophic risk to the capital markets. Sustainability of this source of capital, however, is somewhat questionable as these providers of capital have yet to evolve evaluations of correlations of loss scenarios in their own portfolios just as the insurance industry itself has been forced to do.

As mentioned previously, a feature of the post-2005 wind season market has been the creation of limited life vehicles, commonly known as "sidecars". Sidecars purport to maintain many of the benefits of the traditional reinsurance start-ups and to add other benefits based on the ways in which they differ. Specifically, sidecars are typically privately owned, allowing them to further define their risk/business relationship with the existing company from which they are ceding risk. Several hedge funds and private equity firms have invested in these as a way to gain exposure to underwriting risk.

From the underwriter's perspective, such vehicles offer an opportunity to earn fee income (while sharing some of the equity risk) and to minimize onerous rating agency capital constraints on their own balance sheets. Sidecars also allow the underwriter to manage an overall portfolio of risk by securitizing certain lines of business or risks that may earn incrementally less return on its own balance sheet due to accumulation of exposure, for example.

Sidecars also allow for a certain level of customization of their involvement, a customization that can grow and lessen over time, based on market behaviors. This allows them to respond more readily and quickly to changing dynamics, making them particularly appropriate for catastrophic risk. These vehicles appear to be able to manage capital more effectively than their public counterparts, including ceasing operations altogether. For this reason, they are considered flexible, opportunistic plays on the insurance and reinsurance cycle.

Although recently introduced, Moody's has suggested that the positive reaction to this new innovation, and their ability to be rated consistently will make sidecars an increasingly common function in the reinsurance market. Moody's also suggests that though sidecar structures have been predominant in the catastrophic risk area of the reinsurance market, their success in this sector will pull their use to other sectors in the reinsurance and insurance markets, including life and health insurance.

There is not much investor experience with sidecars, as the majority of them were created following hurricane activity in late 2005. At this point, the relatively untested attribute of sidecars is the substance of the fundamental understanding between the 
sponsor insurance company and the investors in the sidecar. Much like the early securitizations in the banking industry, the sidecar concept will most certainly have to undergo a dramatic evolution resulting in a true meeting of the minds. This is not to suggest that the demise of the sidecar concept is imminent, but, rather, that its evolution will necessarily be supported by substantially improved risk management at the sponsor insurance company to communicate effectively with investors in sidecars.

Regardless of how the sidecar concept evolves, the bottom line is that traditional providers of capital to the industry and newcomers to the industry have more choices today with respect to the deployment of capital to bear the risk our industry has traditionally borne than ever before. The insurance company, therefore, must evolve to compete effectively to generate adequate returns for shareholders.

Apart from investor influences on the convergence of the insurance industry with the capital markets, regulatory forces are working to improve transparency on a global basis and, with the appropriate balance, to support both rational competitive behavior and enhanced enterprise risk management. A good example of such forces at work is the Solvency II initiative in Europe.

As a result of the growing complexities of the industry, the Solvency I framework in Europe is being shored up from above with laws and regulations, and from below by larger organizations with the funds to create their own internal checks and balances. In order to compensate for the growing inefficiencies of Solvency I, countries throughout Europe have independently created laws and regulations to protect organizations and consumers from the risks associated with inordinate or inappropriate direction of capital. Also, recent activity in larger companies to create more extensive, risk-based, internal frameworks in order to develop a more realistic and impartial assessment of the allocation of capital has increased substantially. The implementation of Solvency II will seek to cede the advantageous elements of these independently created internal models, as well as the regulatory advances, and apply them across the European industry.

Solvency II proposes to use the independent internal models as the cornerstone of its design. The immediate goals of this framework are to ensure a high standard of risk assessment, efficient capital allocation, increased transparency and standards by which European companies can function under a common system of control, creating a single market.

Solvency II is based on a three-pillar approach much like Basel II, the banking industry framework. These three pillars operate in tandem but necessarily independently of one another. Broadly, Pillar 1 is the check on financial resources, Pillar 2 operates to make sure these financial resources are being dispersed sensibly and with an eye to risk management, and Pillar 3 determines the amount of transparency and disclosure necessary. No aspect of Solvency II has to do with the location or the size of the company in question, determining a company's solvency solely by the "nature of the business and the risks".

\footnotetext{
${ }^{1}$ CEA \& Towers Perrin Tillinghast (2006, p. 8).
} 
In conclusion, the convergence and interplay between the insurance sector and the capital markets is likely to increase as will the diversity of products the capital markets offer.

The speed and depth of this increase will depend on several issues, two in particular. Firstly, the ability of the insurance sector to improve its data quality and transparency and, secondly, the number and size of large losses in the next several years as the markets develop their knowledge. Those insurers who have the best data collection and control; those who have the ability to "dice and slice" it will have a competitive advantage.

Even with this, however, the industry retains one major unresolved issue, how to handle "timing risk"? The reduction and elimination of equalization reserves matched against the increasing uncertainty of frequency and severity leaves the industry with a fundamental issue.

\section{References}

CEA \& Towers Perrin Tillinghast (2006) Solvency II-Introductory Guide (June 2006), Brussels.

\section{About the Author}

Michael A. Butt has been the Chairman of the Board of AXIS Capital Holdings since September 2002. He is also Chairman of the Board of AXIS Specialty Limited. He has over 40 years of insurance industry experience. From 1982 to 1986, he was the Chairman of Sedgwick Limited and the Vice Chairman of the Sedgwick Group plc. From 1987 to 1992, he served as Chairman and Chief Executive Officer of Eagle Star Holdings plc and Eagle Star Insurance Company. From 1993 to 1998, he was Chief Executive Officer and President of Mid Ocean Limited. From 1998 to August 2002, he was the director of XL Capital Limited. He is also the former director of the Farmers Insurance Group, BAT Industries and Instituto Nazionale delle Assicuranzioni. 